\title{
Catheterization in a patient with end-stage renal disease through persistent left superior vena cava: a rare case report and literature review
}

Huisi $\mathrm{He}^{1 \dagger}$, Bingyang $\mathrm{Li}^{1 \dagger}$, Yiyi Ma ${ }^{2 \dagger}$, Yuqiang Zhang ${ }^{2}$, Chaoyang $\mathrm{Ye}^{2}$, Changlin $\mathrm{Mei}^{2}$, Shengqiang $\mathrm{Yu}^{2}$, Bing Dai ${ }^{2^{*}}$ and Yawei Liu ${ }^{2^{*}}$

\begin{abstract}
Background: Persistent left superior vena cava (PLSVC) is a common vena cava malformation, and drains blood into the right atrium via the dilated coronary sinus in most cases. It is usually asymptomatic and detected incidentally during invasive procedures or imaging. Whether the hemodialysis catheters can be placed in PLSVC is still controversial now (Stylianou et al. Hemodial Int 11:42-45, 2007).

Case presentation: Here we report a rare case of catheterization through PLSVC in an end-stage renal disease (ESRD) male patient whose PLSVC connected with pulmonary vein with insufficient blood flow eventually. Among the other 28 cases included in the literature review, 16 cases were non-tunneled catheter and 12 cases were cuffed, tunneled catheter and most of them could provide adequate blood flow.

Conclusion: PLSVC is a rare malformation and mostly asymptotic, we believe that PLSVC drains blood into the right atrium with enough inner diameter and blood flow can serve as an alternative site for conventional dialysis access. However, the feasibility of hemodialysis catheterization through it and measures to avoid serious complications are still needed to be discussed.
\end{abstract}

Keywords: Persistent left superior vena cava, Hemodialysis catheter, Case report

\section{Background}

Persistent left superior vena cava (PLSVC), known as the residual left superior vena cava, is the most common type of vena cava malformations despite its low incidence. In most cases, PLSVC is clinically asymptomatic due to the lack of hemodynamic abnormalities and is almost always found in invasive procedures or imaging.

Reliable and high-quality vascular access which can provide adequate extracorporeal blood flow is a prerequisite for hemodialysis and serves as a crucial factor for prognosis. Non-cuffed and cuffed, tunneled central venous hemodialysis catheter are both preferred choices for end-stage renal disease (ESRD) patients who have an

\footnotetext{
*Correspondence: czdaibing@smmu.edu.cn; lyw1025@163.com

${ }^{+}$Huisi He, Bingyang Li and Yiyi Ma contributed equally to this work.

2Department of Nephrology, Changzheng Hospital, Naval Medical University,

Shanghai 200433, People's Republic of China

Full list of author information is available at the end of the article
}

urgent need for hemodialysis, especially when arteriovenous fistula or graft are both unavailable.

The presence of PLSVC brings difficulties and risks for central venous catheterization. Whether the hemodialysis catheters can be placed in PLSVC is controversial until now. Here we report a rare case of hemodialysis catheterization in a patient with ESRD through PLSVC, but it ended with insufficient blood flow compared to the previous case reports.

\section{Case presentations}

A 54-year-old hemodialysis patient with a history of multiple central venous catheterizations, arteriovenous fistula, and graft operations was admitted to our unit for the creation of permanent vascular access. After initial screening, an arteriovenous fistula (AVF)/arteriovenous graft (AVG) was deemed not possible due to exhausted 
vasculature of both arms, and a cuffed, tunneled hemodialysis catheter was optioned to be chosen. The right internal jugular vein (IJV) catheterization was attempted under sterile conditions, but the guide-wire could not be advanced more than $10 \mathrm{~cm}$, and the right IJV catheterization was abandoned due to consideration of potential critical stenosis. The left IJV was catheterized with a cuffed, tunneled hemodialysis catheter $(14.5 \mathrm{~F}, 36 \mathrm{~cm}$, Palindrome) thereafter without any complication.

Postoperative chest radiograph showed that the catheter was descending straight through the left border of the mediastinum (Fig. 1). Further computed tomography angiography (CTA) of central veins after removal of the hemodialysis catheter, with three-dimensional reconstruction of vessels, revealed the initial segment of the left IJV was stenosed and an abnormal vessel on the left of the aorta drained blood into the left atrium via pulmonary vein. The vascular malformation of PLSVC was confirmed (Fig. 2).

Finally, we replaced a cuffed, tunneled catheter through the right IJV after DSA-guided balloon dilatation of right brachiocephalic venous stenosis. It was removed due to decreasing blood flow and catheter-related bloodstream infection 3 years later. Thereafter, a new cuffed, tunneled catheter was placed in the left IJV which went through right superior vena cava into the right atrium under digital subtraction angiography (DSA) (Fig. 3). Until now, this patient has conducted hemodialysis through the catheter with blood flow around $300 \mathrm{~mL} / \mathrm{min}$ for 4 years.

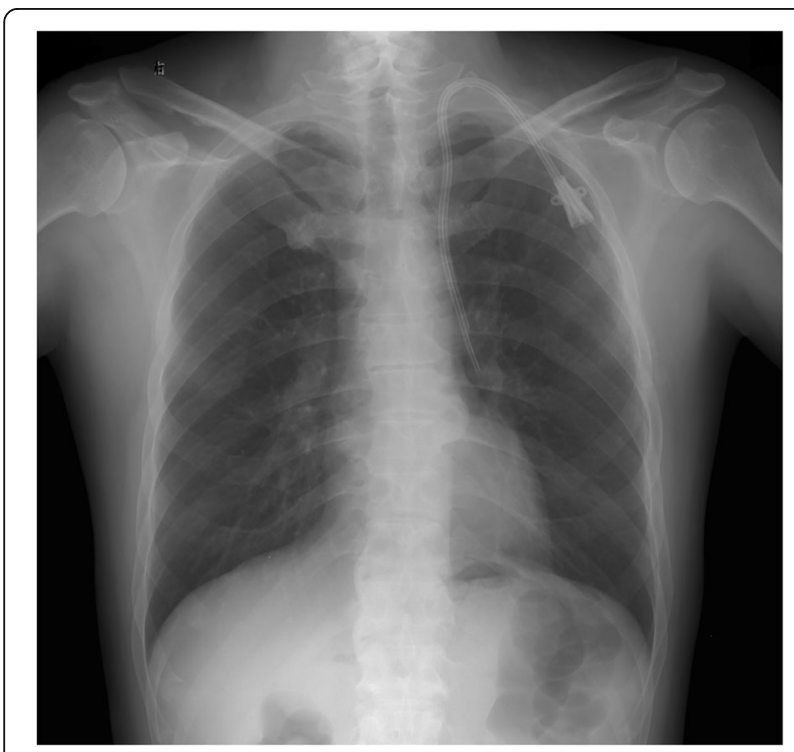

Fig. 1 Postoperative chest radiograph showed the location of the cuffed, tunneled hemodialysis catheter and its abnormal path

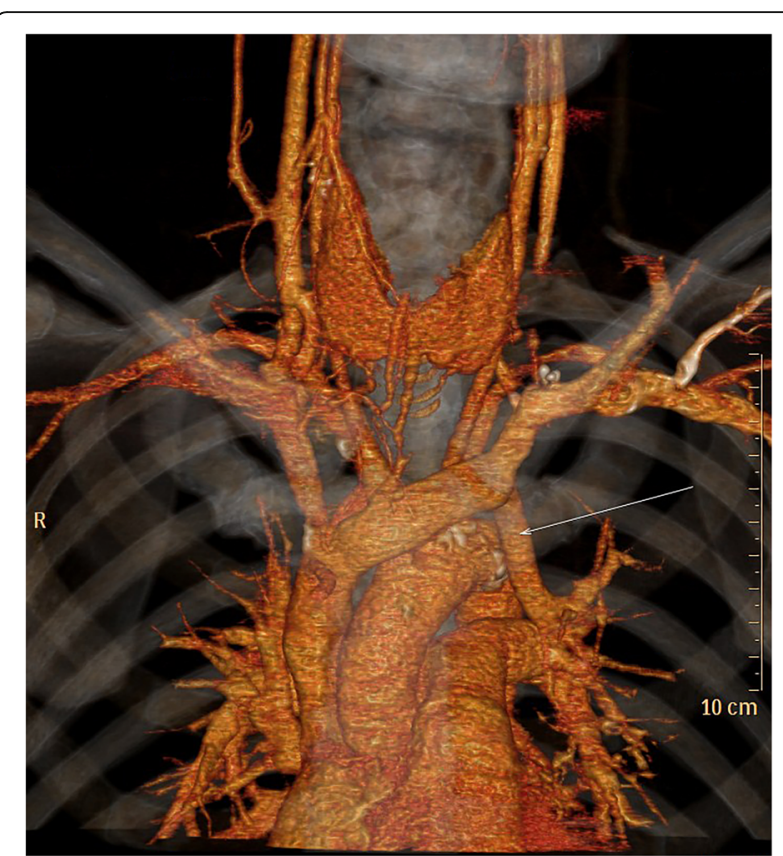

Fig. 2 CTA of central vein and three-dimensional reconstruction confirmed PLSVC which connected with pulmonary vein

\section{Discussion and conclusion}

PLSVC is the most common kind of congenital malformations in the thoracic vessels. It was first reported by Edwards et al. [1] in 1950 and the latest studies show that the incidence of this deformity is about $0.1-0.5 \%$ of the total population, [2] of which about $10 \%$ of patients with congenital heart abnormalities [3, 4].

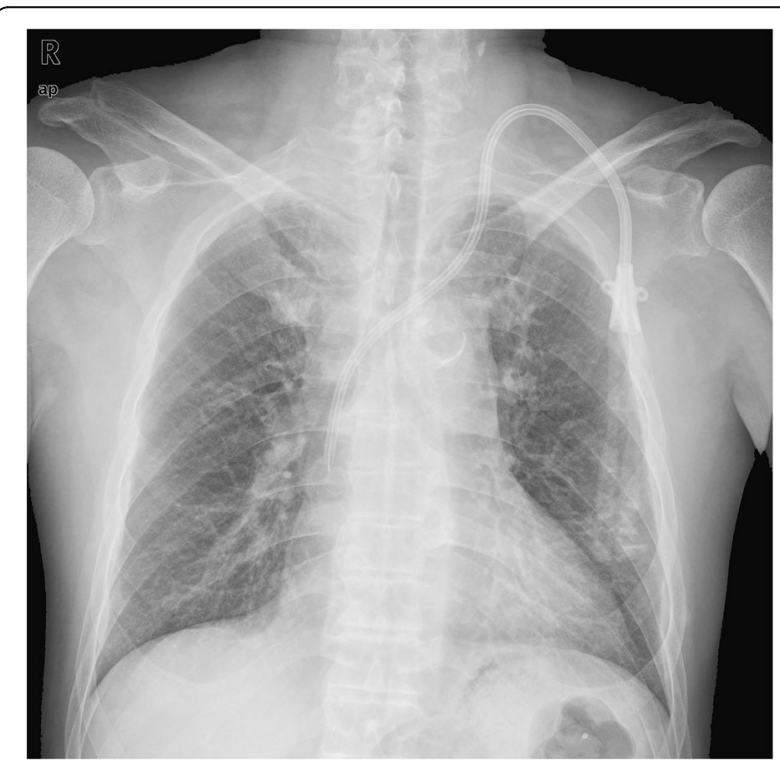

Fig. 3 The chest radiograph of the cuffed, tunneled hemodialysis catheter used now 
Table 1 Schummer's classification of superior vena cava

\begin{tabular}{ll}
\hline Types & Characteristics \\
\hline II & Normal superior vena cava anatomy \\
IIIa $\quad \begin{array}{l}\text { PLSVC and the right superior vena cava exist, with left } \\
\text { brachiocephalic vein between both sides }\end{array}$ \\
IIIb $\quad \begin{array}{l}\text { PLSVC and the right side of the superior vena cava, withoutleft } \\
\text { brachiocephalic vein between both sides }\end{array}$
\end{tabular}

Human left superior vena cava originates in the third week of the embryonic period, and then the left anterior cardinal vena cava gradually atrophies with embryonic development and finally degenerates into the ligament of Marshall. If the degeneration is not complete, then the remains of a pipeline structure after birth is PLSVC. Some clinicians advocate that it associates with chromosomal aberration, congenital cardiac defect, and extracardiac anomalies might be detected at follow-up [5].
Schummer [6] raised the most recognized classification of the supracardial venous system according to anatomic relationships of superior vena cava and its adjacent (Table 1, Fig. 4). The patient in our case had a type IIIa venous malformation.

Ninety-two precent \% of PLSVC patients drain blood into the right atrium via the dilated coronary sinus, [7] most of them are asymptomatic and have no hemodynamic abnormalities. In most cases, it's hard to be detected by physical examination and it is always noticed accidentally during imaging or the process of intravascular invasive procedure such as pacemaker implantation, PICC, cardiac electrophysiological examination and central venous hemodialysis catheterization. However, some patients still show abnormal sinus rhythm or bradycardia at the very beginning. In these cases, the patients might undergo pacemaker implantation because of sick sinus syndrome resulting from histological abnormalities caused by an enlarged
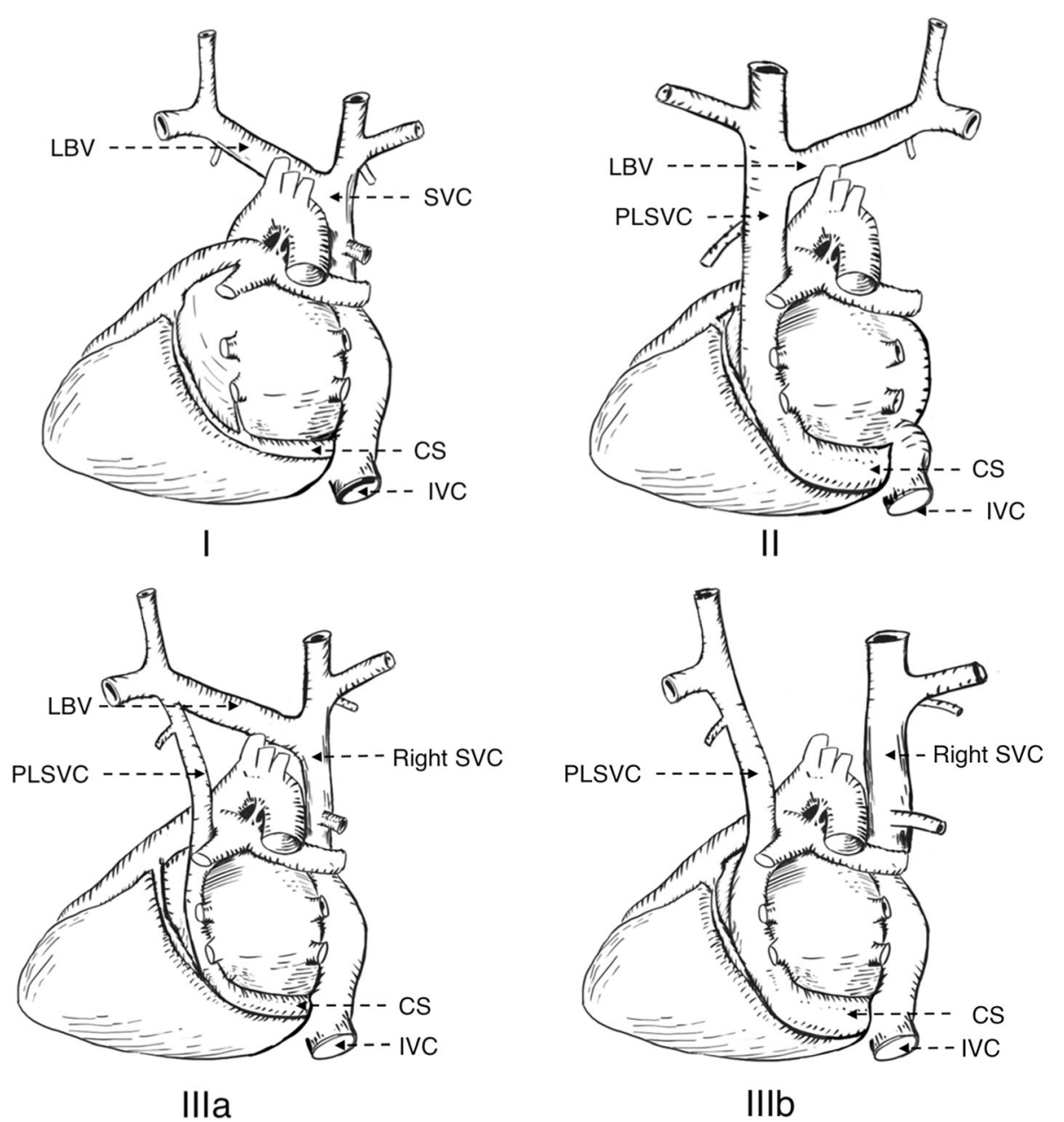

Fig. 4 Schummer's classification of superior vena cava in dorsal view (SVC: Superior vena cava PLSVC: Persistent left superior vena cava LBV: Left brachiocephalic vein CS: Coronary sinus IVC: Inferior vena cava) 
Table 2 Zhu's classification of PLSVC

\begin{tabular}{ll}
\hline Types & Characteristics \\
\hline A & PLSVC drains blood to right atrium via coronary sinus \\
B & PLSVC drains blood to right atrium via coronary sinus with \\
C & partial right-to-left shunt \\
D & $\begin{array}{l}\text { PLSVC drains blood to left atrium directly with right-to-left shunt } \\
\text { sinus absent) }\end{array}$ \\
\hline
\end{tabular}

coronary sinus $[8,9]$. Another $8 \%$ of patients drain blood into left atrium may have obvious clinical cyanosis due to the left to right shunt, and those people always suffer from septal defect, ventricular septal defect or other cardiovascular malformations $[10,11]$. This patient's PLSVC drains blood into the left atrium via pulmonary vein (Type $\mathrm{D}$ in Zhu's classification of PLSVC), but he doesn't have congenital heart disease and cyanosis which may result from low shunt flow volume (Table 2, Fig. 5) [12].

Can persistent left superior vena cava be used in the hemodialysis catheterization? After a careful literature review, totally 28 cases with hemodialysis catheterization through PLSVC were reported. The details of case reports with hemodialysis catheterization through PLSVC are shown in Table 3. Among them, 16 cases were non-tunneled catheter and 12 cases were cuffed, tunneled catheter. Most of them were type III PLSVC with indwelling catheters in left IJV. The previous history of pacemaker implantation was also notable in the latest case we reported [39]. Among these cases, most operations were completed safely, and hemodialysis catheters met the needs of hemodialysis during the maximum 32-month dwelling time. There was one case reported severe hypotension, bradycardia, and cardiac-respiratory arrest after three times successful hemodialysis. Although the correlation between catheterization and arrhythmia was uncertain, the catheter was removed after the fourth hemodialysis was performed [17]. In another case, rare complication pericardial effusion and bilateral pleural effusions were confirmed by chest computed tomogram since short of breath developed 24 $\mathrm{h}$ after catheterization and hemodialysis. This catheter was removed by the cardiothoracic surgeon for safety [28]. In a recently released case, stagnation of blood flow and thrombus formation was found due to a large catheter caliber-to-vein ratio, which resulted in catheter removal after $4 \mathrm{~h}$ [38]. Our case is the first hemodialysis patient with PLSVC that drains blood into the left atrium via pulmonary vein, which leads to insufficient blood flow after catheterization. From this rare case and previously reported cases, we raise some concerns about catheterization in PLSVC.

Firstly, the operators should raise awareness of cardiovascular abnormalities during the central venous access.
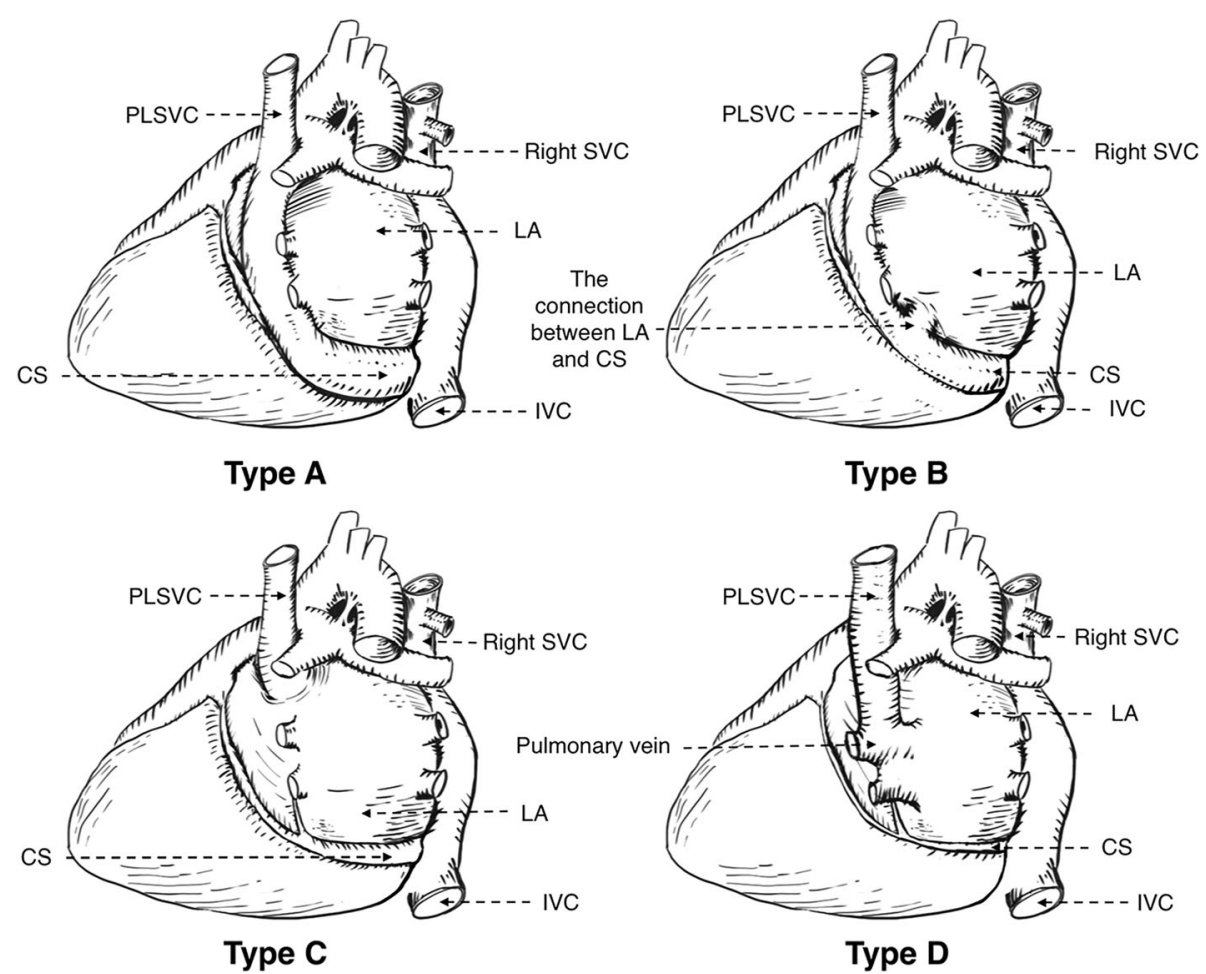

Fig. 5 Zhu's classification of PLSVC in dorsal view (SVC: Superior vena cava PLSVC: Persistent left superior vena cava CS: Coronary sinus LA: Left atrium IVC: Inferior vena cava) 


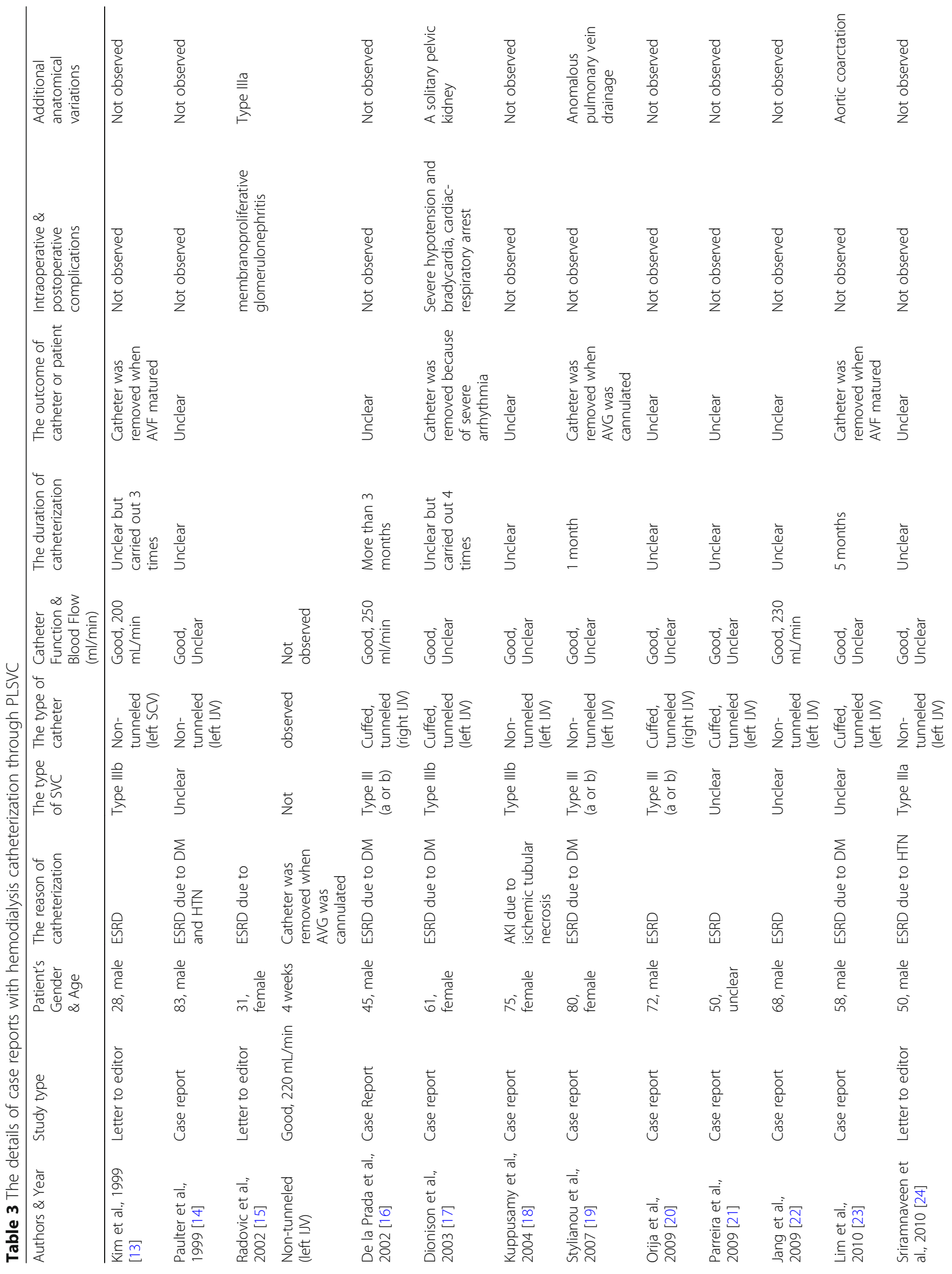




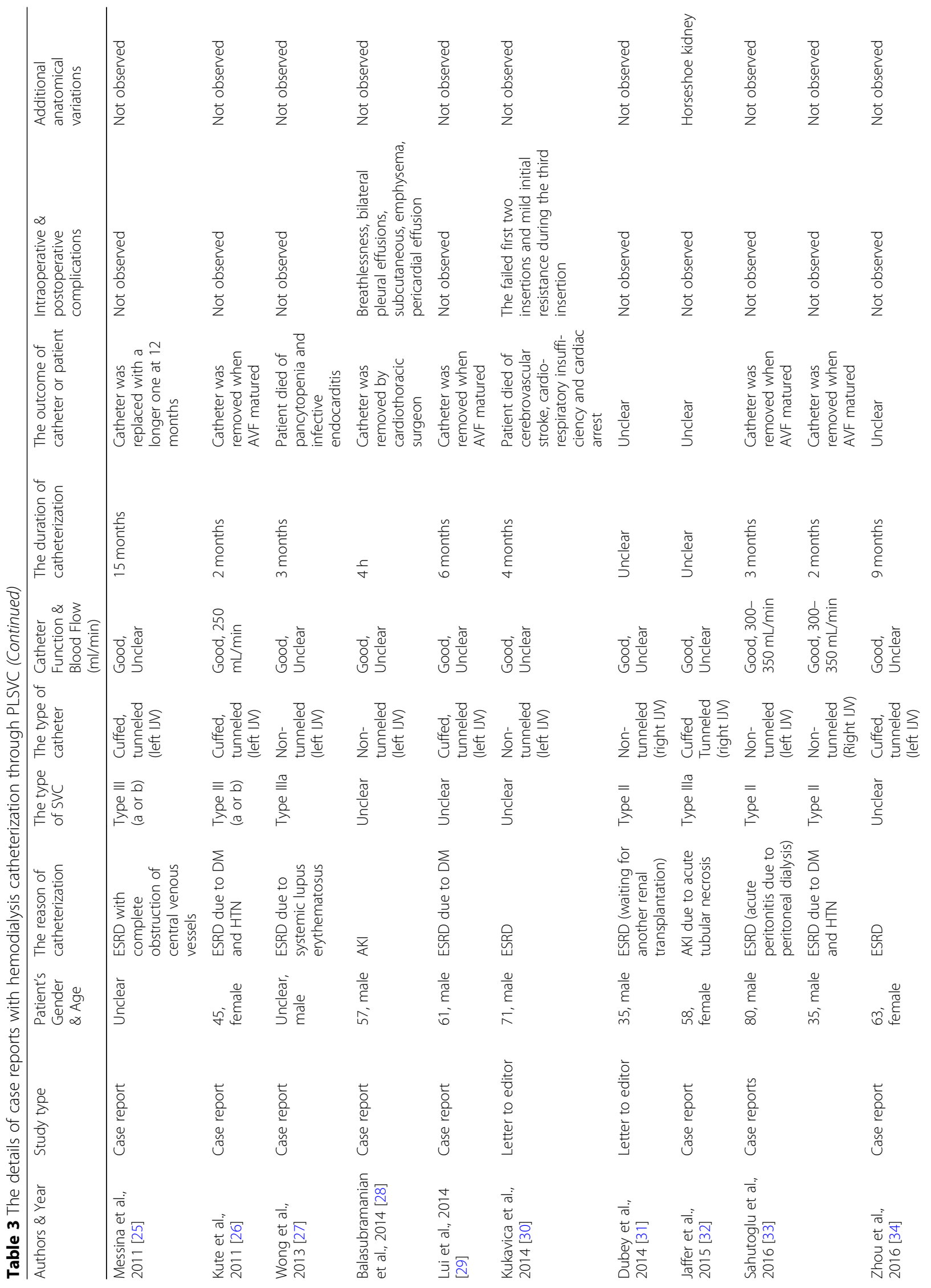


$\begin{array}{ll}\text { He et al. BMC Nephrology } & \text { (2019) 20:202 }\end{array}$

Page 7 of 10

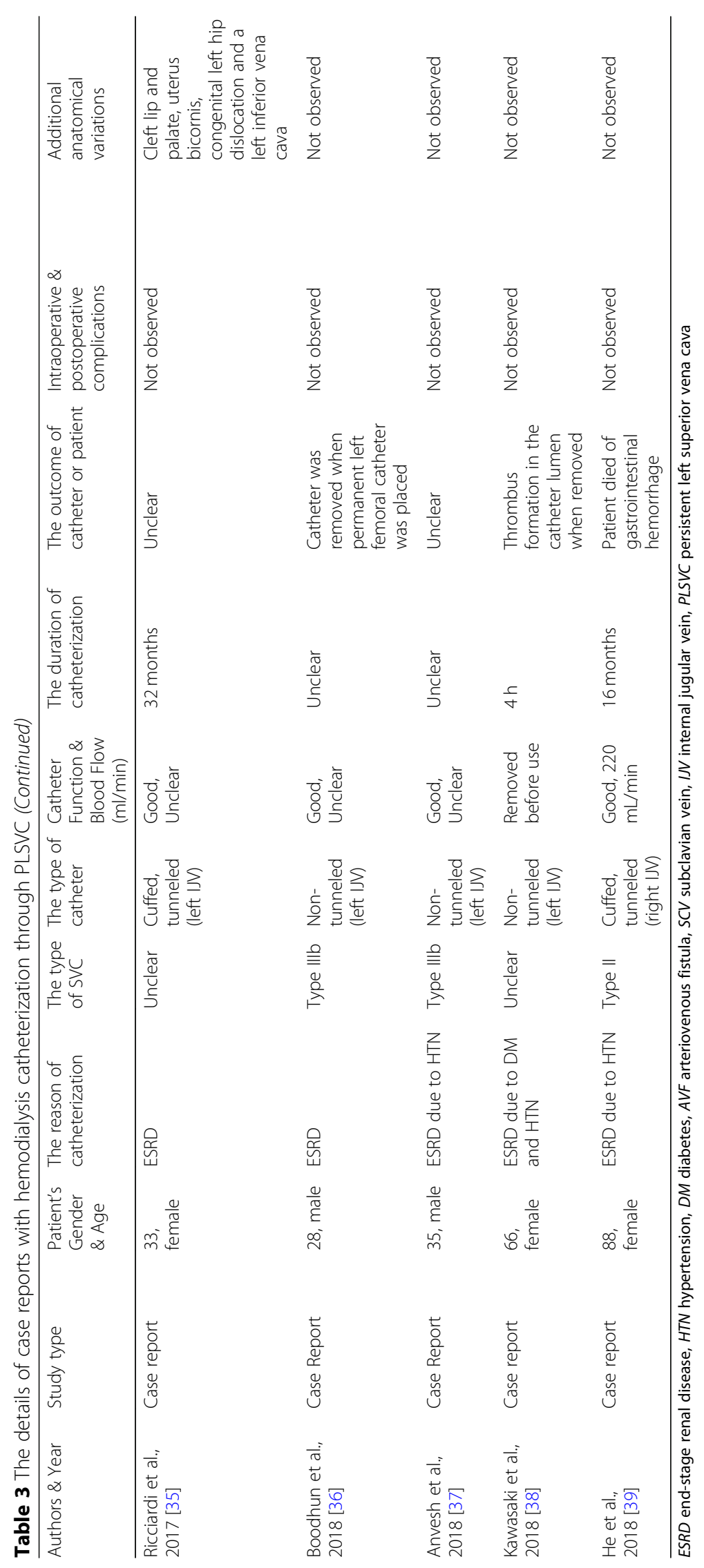


For suspected patients with positive symptoms and signs, echocardiography should perform as soon as possible. The direct signs are the existence of the duct-like structure and the blood flow spectrum in the left upper part of the chest, and the indirect sign is the dilated coronary sinus [40]. In addition, unexplained tricuspid atrial systolic murmur and right atrial enlargement should arouse attention. Localized bullae in front of the mediastinum in chest radiography is an important sign of early screening and echocardiography can be the primary screening method. Cardiac catheterization procedure is the gold standard for the diagnosis of PLSVC. However, its invasiveness, radioactivity prohibits clinical use. Thoracic enhanced CTA might serve as an alternative.

Secondly, left IJV is a preferred cannulation site for hemodialysis catheterization through PLSVC, especially for those patients with absent right superior vena cava. Traditionally, right IJV cannulation is generally preferred in hemodialysis patients due to its straight path directly into the superior vena cava and fewer complications compared with other positions. Nevertheless, in these PLSVC without right superior vena cava cases, since the right IJV and subclavian vein drains blood into PLSVC via the right brachiocephalic vein, traditional right IJV cannulation may encounter difficulties and acute complications normally met in left IJV cannulation. Central vein perforation, pneumothorax, and artery puncture all have been reported in previous cases, which mostly caused by force during the operation without the sense of cardiovascular malformations. So, whenever any resistance is met with forwarding the guidewire or the peel-away sheath, do not push by force, what you need is to pull it out and reassess vascular condition (especially for PLSVC with absent right superior vena cava). Detailed history survey, preoperative imaging screening, intraoperative fluoroscopic guidance, and postoperative chest radiograph assessment for suspected patients are priority points to avoid serious complications.

Thirdly, whether a hemodialysis catheter can be placed in PLSVC is still controversial until now [19]. Our case proved that the PLSVC which rarely drains blood into the left atrium via pulmonary vein or left-to-right shunt cannot be used to conduct hemodialysis because of obvious hemodynamic abnormalities and insufficient blood flow. In most cases, PLSVC flowed back into the right atrium through the coronary venous sinus. Although few complications were reported in the placement of a non-tunneled hemodialysis catheter through PLSVC (Table 3), hemodynamic changes after indwelling catheters in those patients potentially may lead to angina pectoris, arrhythmia, stroke, cardiac arrest due to coronary sinus irritation. In severe cases, it may threaten the patients' life [19, 22, 41]. Some nephrologists believe that PLSVC is relatively thin and the blood flow is not enough to maintain long-term hemodialysis, and the locally generated turbulence may increase the probability of thrombosis and arrhythmia. However, if the diameter of PLSVC and blood flow were sufficient, with stably flowed back through the coronary venous sinus into the right atrium, it was feasible to dwell a hemodialysis catheter in PLSVC for long-term hemodialysis. We believe that after an accurate assessment of intrathoracic vessels including the inner diameter of PLSVC via preoperative imaging, a PLSVC can serve as an alternative site for conventional dialysis access.

However, the location of the catheter tip remains to be elucidated. The tip of the cuffed, tunneled hemodialysis catheter is normally positioned within the right atrium or at the junction of superior vena cava and right atrium. For PLSVC patients, the right atrium is inaccessible and the placement of catheter tip in the left superior vena cava that is close to the coronary sinus might cause arrhythmia, so we think that the lower left superior vena cava with adequate blood flow and negative cardiac effect might be an optimal choice.

PLSVC is a rare and asymptotic malformation, so the early detection and diagnosis before hemodialysis catheterization are quite difficult. Detailed history survey, echocardiography and preoperative imaging screening are the priority points to identify suspect patients. Rarely, the PLSVC which drains blood into the left atrium via pulmonary vein or left-to-right shunt should be excluded. During the surgery, intraoperative ultrasound and fluoroscopic guidance are strongly recommended if available. Performing catheterization carefully, position it properly and do not push it by force may help to avoid serious complications. We believe that PLSVC drains blood into the right atrium with enough inner diameter and blood flow can serve as an alternative site for conventional dialysis access. Besides, the preferable location of the catheter's tip with minor hemodynamic effect remained to be determined.

\section{Abbreviations \\ AVG: arteriovenous graft; CTA: Computed tomography angiography; DSA: Digital subtracted angiography; ESRD: End-stage renal disease;} IJV: Internal jugular vein; PLSVC: Persistent left superior vena cava

\section{Acknowledgements}

The authors thank the patient and his family for their support.

\section{Funding}

This paper is supported by the National Natural Science Foundation of China (grant no. 81370844). The funding sources had no role in the design of the study; collection, analysis, and interpretation of data; or writing of the manuscript.

\section{Availability of data and materials}

All data collected from this patient were obtained from the Changzheng Hospital and are available in this paper. 


\section{Authors' contributions}

$\mathrm{HSH}, \mathrm{BYL}, \mathrm{YYM}, \mathrm{YWL}$ and $\mathrm{BD}$ were all directly involved in the care of the patient. HSH and BYL acquired the data necessary for analysis and wrote the initial draft of the paper. YYM, YQZ, CYY, CLM and SQY contributed in data analysis and interpretation. BD and YWL were responsible for revising the manuscript. All authors approved the final version of the manuscript prior to submission. All authors agreed to be accountable for all aspects of the final manuscript.

\section{Ethics approval and consent to participate} Not applicable.

\section{Consent for publication}

The patient received all information regarding this case report. Written informed consent for publication in BMC Nephrology was obtained from the patient.

\section{Competing interests}

The authors declare that they have no competing interests.

\section{Publisher's Note}

Springer Nature remains neutral with regard to jurisdictional claims in published maps and institutional affiliations.

\section{Author details}

${ }^{1}$ Naval Clinical Medicine Grade 2014, Basic Medical College, Naval Medical University, Shanghai 200433, People's Republic of China. '2Department of Nephrology, Changzheng Hospital, Naval Medical University, Shanghai 200433, People's Republic of China.

Received: 28 November 2018 Accepted: 15 April 2019

Published online: 04 June 2019

\section{References}

1. Edwards JE, DuSHANE JW, Alcott DL, Burchell HB. Thoracic venous anomalies III. Atresia of the common pulmonary vein, the pulmonary veins draining wholly into the superior vena cava. AMA Arch Pathol. 1951;51(4):446-60.

2. Ghaye B. Imaging of hila and pulmonary vessels. In: Comparative Interpretation of CT and Standard Radiography of the Chest. Medical radiology. Berlin, Heidelberg: Springer; 2011. p. 165-94. https://doi.org/10. 1007/978-3-540-79942-9_7.

3. Sheikh AS, Mazhar S. Persistent left superior vena cava with absent right superior vena cava: review of the literature and clinical implications. Echocardiography. 2014;31(5):674-9. https://doi.org/10.1111/echo.12514.

4. Cheng Z, Deng H, Cheng K, Chen T, Gao P, Fang Q. Implantation of a pacemaker in a patient with persistent left superior vena cava and absence of right superior vena cava. Int J Cardiol. 2013;168(2):e53-4. https://doi.org/ 10.1016/j.ijcard.2013.06.108.

5. Du L, Xie H-N, Zhu Y-X, Li-Juan L, Peng R, Zheng J. Fetal persistent left superior vena cava in cases with and without chromosomal anomalies. Prenat Diagn. 2014;34(8):797-802. https://doi.org/10.1002/pd.4380.

6. Schummer W, Schummer C, Fröber R. Persistent left superior vena cava and central venous catheter position: clinical impact illustrated by four cases. Surg Radiol Anat. 2003;25(3-4):315-21. https://doi.org/10.1007/s00276-003-0138-6.

7. Arat N, Sokmen Y, Golbasi Z. Persistent left superior vena cava with absent right superior vena cava and coronary sinus dilation mimicking a Paracardiac mass. Tex Heart Inst J. 2007;34(4):492-3.

8. Umar F, Alzuwam A, Osman F. Dual-chamber pacemaker in persistent left superior vena cava. Heart. 2011;97(16):1360. https://doi.org/10.1136/heartjnl2011-300145.

9. James TN, Marshall TK, Edwards JE. De subitaneis mortibus. XX. Cardiac electrical instability in the presence of a left superior vena cava. Circulation. 1976;54(4):689-97.

10. Yener N, Sürücü HS, Dogan R, Aldur MM. A case with dextrocardia, ventricular septal defect, persistent left superior vena cava and drainage of the great cardiac vein into the left internal thoracic vein. Surg Radiol Anat. 2001:23(3):205-6. https://doi.org/10.1007/s00276-001-0205-9.

11. Demirtürk $O S$, Gümüs $A$, Ülger $M H$, Güvener $M$. An absent right superior vena cava with a persistent left superior vena cava combined with the presence of a ventricular septal defect in a pediatric patient: implications for surgical correction. Turkish Journal of Thoracic \& Cardiovascular Surgery. 2012;20(3):638-40.

12. Zhu X. Basic Illustrations For Cardiac Surgery. 2nd ed. Beijing: Peking union medical college press; 2010. p. 257-64.

13. Kim YO, Choi EJ, Jeon HK, et al. Persistent left superior vena cava detected by hemodialysis catheterization. Nephron. 1999;83(1):87-8. https://doi.org/ 10.1159/000045478

14. Pautler S, Muirhead N. Soft-tissue images. Persistent left superior vena cava. Can J Surg. 1999;42(1):7.

15. Radovic M, Masulovic D, Djukanovic L. Displacement of hemodialysis catheter in persistent left superior caval vein. Ren Fail. 2002;24(3):383-5.

16. de la Prada FJ, Sastre M, Forteza JF, Morey A, Munar MA, Alarcón A. Persistence of the left superior vena cava discovered during the implantation of a hemodialysis catheter. Nefrologia. 2002;22(2):199-201.

17. Dionisio $\mathrm{P}$, Borsetti $\mathrm{C}$, Valenti $\mathrm{M}$, et al. Knowledge of the anomalies of the big central veins reduces the morbidity during the cannulation for hemodialysis: description of a case of persistent left superior vena cava and revision of literature. J Vasc Access. 2003;4(1):25-31. https://doi.org/10.5301/ JVA.2008.3680.

18. Kuppusamy TS, Balogun RA. Unusual placement of a dialysis catheter: persistent left superior vena cava. Am J Kidney Dis. 2004;43(2):365-7.

19. Stylianou K, Korsavas K, Voloudaki A, et al. Can a left internal jugular catheter be used in the hemodialysis of a patient with persistent left superior vena cava? Hemodial Int. 2007;11(1):42-5. https://doi.org/10.1111/j. 1542-4758.2007.00152.x

20. Orija A, Rajan J, Degenhard A. An interesting case: bilateral superior vena cava in a patient with end stage renal disease. Semin Dial. 2009;22(2):209-11. https://doi.org/10.1111/j.1525-139X.2008.00538.x.

21. Parreira LF, Lucas CC, Gil CC, Barata JD. Catheterization of a persistent left superior vena cava. J Vasc Access. 2009;10(3):214-5. https://doi.org/10.1177/ 112972980901000315

22. Jang YS, Kim SH, Lee DH, Kim DH, Seo AY. Hemodialysis catheter placement via a persistent left superior vena cava. Clin Nephrol. 2009;71(4):448-50.

23. Lim TC, H'ng MW. Persistent left superior vena cava: a possible site for haemodialysis catheter placement. Singap Med J. 2010;51(12):e195-7.

24. Sriramnaveen P, Krishna Kishore C, Sainaresh W, et al. Placement of dual lumen non-cuffed dialysis catheter into persistent left superior vena cava. Clin Nephrol. 2010;73(1):81-2.

25. Messina M, Morale W, Viglianesi A, et al. Atypical placement of hemodialysis catheters in patients with complete and irreversible obstruction of central venous vessels. J Vasc Access. 2011;12(1):21-7.

26. Kute VB, Vanikar AV, Gumber MR, Shah PR, Goplani KR, Trivedi HL. Hemodialysis through persistent left superior vena cava. Indian J Crit Care Med. 2011;15(1):40-2. https://doi.org/10.4103/0972-5229.78223.

27. Wong KW, Yap FL. Persistent left superior vena cava diagnosed during haemodialysis catheter placement - a case report. Med J Malaysia. 2013:68(4):360-1.

28. Balasubramanian S, Gupta S, Nicholls M, Laboi P. Rare complication of a dialysis catheter insertion. Clin Kidney J. 2014;7(2):194-6. https://doi.org/10. 1093/ckj/sfu006

29. Lui WL, Kuang LE, Ren LC, Renaud CJ. Safe maintenance of left-sided chronic accesses in a persistent left superior vena cava in the presence of normal coronary sinus calibre. Nephrology (Carlton). 2014;19(2):116-8. https://doi.org/10.1111/nep.12174.

30. Kukavica N, Resic H, Spasovski G. Atypical vascular access for dialysis patients via persistent left superior vena cava. Ther Apher Dial. 2014;18(1):112-3. https://doi.org/10.1111/1744-9987.12162.

31. Dubey PK, Kumar N, Sanjeev OP. Misplacement of a right internal jugular hemodialysis catheter in a persistent left superior vena cava. J Clin Anesth 2014;26(1):84-5. https://doi.org/10.1016/j.jclinane.2013.07.012.

32. Jaffer $F$, Chandiramani V. Concomitant persistent left superior vena cava and horseshoe kidney. Case Rep Nephrol. 2015;2015:178310. https://doi.org/10. 1155/2015/178310.

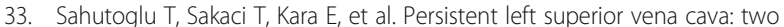
case reports and a review from nephrologists' perspective. Hemodial Int. 2016;20(3):369-77. https://doi.org/10.1111/hdi.12389.

34. Zhou Q, Murthy S, Pattison A, Werder G. Central venous access through a persistent left superior vena cava: a case series. J Vasc Access. 2016:17(5): e143-7. https://doi.org/10.5301/jva.5000554. 
35. Ricciardi B, Ricciardi CA, Lacquaniti A, et al. Persistent left superior vena cava and partially left inferior vena cava: a case report of a dangerous central venous catheterization. J Vasc Access. 2017;18(5):e66-9. https://doi.org/10. 5301/jva.5000722.

36. Boodhun M, Mohammad N, Adnan A, Wan Ghazali WS. Catheterisation of a persistent left superior vena cava. BMJ Case Rep. 2018;2018. https://doi.org/ 10.1136/bcr-2018-224355.

37. Anvesh G, Raju SB, Rammurti S, Prasad K. Persistent left superior vena cava in a hemodialysis patient. Indian J Nephrol. 2018;28(4):317-9. https://doi. org/10.4103/ijn.IJN_245_17.

38. Kawasaki T, Tanaka H, Oba M, Takada M, Tanaka H, Suda S. Persistent left superior vena cava with thrombus formed in the catheter lumen $4 \mathrm{~h}$ after dialysis catheter placed. CEN Case Rep. 2018;7(1):158-61. https://doi.org/10. 1007/s13730-018-0317-2.

39. He H, Li B, Gao X, et al. A dialysis patient with isolated persistent left superior vena cava. Kl. 2018. https://doi.org/10.1016/j.kint.2018.08.008.

40. Yuce M, Kizilkan N, Kus E, Davutoglu V, Sari I. Giant coronary sinus and absent right superior vena cava. Vasa. 2011;40(1):65-7. https://doi.org/10. 1024/0301-1526/a000071.

41. Granata A, Andrulli S, Fiorini F, et al. Persistent left superior vena cava: what the interventional nephrologist needs to know. J Vasc Access. 2009;10(3): 207-11. https://doi.org/10.1177/112972980901000313.

Ready to submit your research? Choose BMC and benefit from:

- fast, convenient online submission

- thorough peer review by experienced researchers in your field

- rapid publication on acceptance

- support for research data, including large and complex data types

- gold Open Access which fosters wider collaboration and increased citations

- maximum visibility for your research: over $100 \mathrm{M}$ website views per year

At BMC, research is always in progress.

Learn more biomedcentral.com/submissions 